\title{
Molecular structure and DFT investigations on new cobalt(II) chloride complex with superbase guanidine type ligand
}

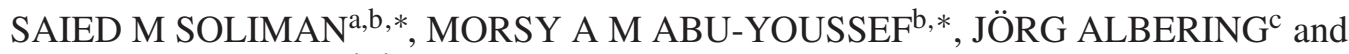 \\ AYMAN EL-FAHAM ${ }^{b, d}$ \\ a Department of Chemistry, College of Science \& Arts, King Abdulaziz University, \\ P.O. Box 344 Rabigh 21911, Saudi Arabia \\ ${ }^{b}$ Department of Chemistry, Faculty of Science, Alexandria University, P.O. Box 426 Ibrahimia, \\ 21321 Alexandria, Egypt \\ ${ }^{\mathrm{c}}$ Graz University of Technology, Mandellstrasse 11 (III), A-8010 Graz, Austria \\ ${ }^{\mathrm{d} D e p a r t m e n t}$ of Chemistry, College of Science, King Saud University, P.O. Box 2455, Riyadh 11451, \\ Saudi Arabia \\ e-mail: saied1soliman@yahoo.com; morsy5@Alexu.edu.eg; joerg.albering@tugraz.at; \\ aymanel_faham@hotmail.com
}

MS received 1 June 2015; revised 24 July 2015; accepted 10 August 2015

\begin{abstract}
The new [Co(btmgn) $\left.\mathrm{Cl}_{2}\right]$ complex and the 1,8-bis(tetramethylguanidino)naphthalene (btmgn) ligand were synthesized and characterized. The X-ray single crystal investigation showed distorted tetrahedral geometry around the $\mathrm{Co}(\mathrm{II})$ ion. The geometry of the btmgn and $\left[\mathrm{Co}(\mathrm{btmgn}) \mathrm{Cl}_{2}\right]$ complex was optimized using the B3LYP/6-311G(d,p) method. The calculated geometric parameters at the optimized structure of the $[\mathrm{Co}$ (btmgn $\left.) \mathrm{Cl}_{2}\right]$ complex showed good agreement with our reported X-ray structure. The two tetramethylguanidino groups are in a cis-type position to the naphthalene ring plane both in the free and coordinated btmgn. The large red shift of the $v_{\mathrm{C}=\mathrm{N}}$ mode upon coordination indicates the strong ligand-metal interactions. The calculated natural charges using natural bond orbital (NBO) analysis at the two coordinated Cl-atoms are not equivalent. Also the two $\mathrm{LP}(4) \mathrm{Cl} \rightarrow \mathrm{LP}^{*}(3) \mathrm{Co}$ intramolecular charge transfer interaction energies $\left(\mathrm{E}^{(2)}\right)$ are 29.00 and $39.17 \mathrm{kcal} / \mathrm{mol}$, respectively. The two $\mathrm{Co}-\mathrm{Cl}$ bonds are not equivalent where the longer $\mathrm{Co}-\mathrm{Cl}$ bond has more electronegative chlorine atom than the shorter one. Molecular electrostatic potential (MEP) study of the btmgn ligand showed that the N4 and N7 atoms are the most reactive nucleophilic centers for the coordination with the $\mathrm{Co}^{2+}$ ion. The $\left[\mathrm{Co}(\right.$ btmgn $\left.) \mathrm{Cl}_{2}\right]$ complex has higher polarizability $\left(\alpha_{0}\right)$, first hyperpolarizability $\left(\beta_{0}\right)$ and lower energy gap $(\Delta \mathrm{E})$ than the free ligand. The TD-DFT calculations predicted the transition bands at 337.2 $\mathrm{nm}(\mathrm{f}=0.2299, \mathrm{H} \rightarrow \mathrm{L})$ and $342.6 \mathrm{~nm}(\mathrm{f}=0.1465, \mathrm{H}-2 / \mathrm{H} \rightarrow \mathrm{L})$ for the btmgn and $\left[\mathrm{Co}(\mathrm{btmgn}) \mathrm{Cl}_{2}\right]$, respectively.
\end{abstract}

Keywords. Guanidine; superbases; Cobalt(II); DFT; NBO; MEP.

\section{Introduction}

In the past decades, a number of organic proton sponges and superbases were synthesized and applied for various purposes. ${ }^{1}$ The classical proton sponge 1,8 bis(dimethylamino)naphthalene was described already in 1968 by Alder et al. ${ }^{2}$ More recently, Sundermeyer et al. reported on the new superbasic proton sponge 1,8bis(tetramethylguanidino)naphthalene (btmgn) as an example for an aromatically bridged bisguanidine. ${ }^{3}$ Due to resonance stabilization of the conjugated acid, guanidines are much stronger bases than amines. In coordination chemistry, the neutral guanidine ligands represent not only excellent $\sigma$-donor, but also $\pi$-donor ligands. ${ }^{4,5}$ In the last decade, the design of organic-inorganic hybrid mesoporous materials with strong basic functionalities

\footnotetext{
*For correspondence
}

has attracted great attention because of their potential applications in heterogeneous catalysis for the synthesis of fine chemicals. ${ }^{6}$ The peralkylated bifunctional nitrogen ligands of $\mathrm{Cu}$ and $\mathrm{Fe}$ were designed and used in the field of biomimetic coordination chemistry. ${ }^{7,8}$ Also, the Mo and $\mathrm{Ru}$ complexes of these ligands were prepared and their catalytic performance in the hydrogenation process was demonstrated. ${ }^{9}$ Late-transition metals, especially $\mathrm{Ni}, \mathrm{Pd}$, and $\mathrm{Pt}$ coordinated to diimine ligands were used to catalyze polymerization of ethylene and other $\alpha$-olefin molecules..$^{10}$ Moreover, guanidine groups (arginine, creatine) play an important role in biological systems, in particular for proton transfer processes in proton channels. ${ }^{11,12}$ Studies of the structural, electronic and spectroscopic properties of guanidine ligands containing aromatic group as potentially strong electron donors and their complexes with $\mathrm{Co}(\mathrm{II})$ and $\mathrm{Ni}$ (II) were still rare in literature. ${ }^{13-15}$ 
In the present work the new $\mathrm{CoCl}_{2}$ complex of the guanidine-type ligand, bis(tetramethylguanidino) naphthalene (btmgn) has been synthesized. The ligand and the new $\left[\mathrm{Co}(\mathrm{btmgn}) \mathrm{Cl}_{2}\right]$ complex were characterized using different spectroscopic techniques. The $\mathrm{X}$-ray structure of the $\left[\mathrm{Co}(\mathrm{btmgn}) \mathrm{Cl}_{2}\right]$ complex is determined. The electronic and spectroscopic aspects of the ligands as well as the $\left[\mathrm{Co}(\mathrm{btmgn}) \mathrm{Cl}_{2}\right]$ were discussed with the aid of DFT quantum chemical calculations.

\section{Experimental and Computational}

\subsection{General}

The solvents used were of HPLC reagent grade. Melting points were determined with a Mel-Temp apparatus and are uncorrected. Magnetic resonance spectra $\left({ }^{1} \mathrm{H}\right.$ NMR and ${ }^{13} \mathrm{C}$ NMR spectra) were recorded on a JOEL 400 $\mathrm{MHz}$ spectrometer with chemical shift values reported in $\delta$ units (ppm) relative to an internal standard. Followup of the reactions and checks of the purity of the compounds was done by TLC on silica gel-protected aluminum sheets (Type 60 GF254, Merck) and the spots were detected by exposure to UV-lamp at $\lambda=254 \mathrm{~nm}$ for a few seconds.

\subsection{Synthesis of 1,8-bis(tetramethylguanidino) naphthalene (btmgn $)^{3}$}

Chloroformamidinium salt 1 (TCFH, 5.7 g, $20 \mathrm{mmol}$ ) was added slowly to a solution of 1,8-diaminonaphthalene $2(1.6 \mathrm{~g}, 10 \mathrm{mmol})$ and triethylamine $(2.0 \mathrm{~g}, 20$ $\mathrm{mmol}$ ) in $10 \mathrm{~mL}$ DMF. The reaction was carried out at $90^{\circ} \mathrm{C}$ in a water bath for $6 \mathrm{~h}$. The mixture was left to cool to room temperature, and then poured into $50 \mathrm{~mL}$ of ice cold water. The solid product formed was filtered directly and then washed with water. The crude product btmgn was recrystallized from $\mathrm{CH}_{2} \mathrm{Cl}_{2} / \mathrm{n}$-hexane.

The product btmgn was obtained as a gray solid in $76 \%$ yield, M.p. $214-216^{\circ} \mathrm{C}(\mathrm{dec}) . \mathrm{R}_{\mathrm{f}}: 0.59\left(\mathrm{CH}_{2} \mathrm{Cl}_{2} /\right.$ $\mathrm{MeOH}$ 9:1). IR (KBr, $\left.\mathrm{cm}^{-1}\right)$ : 3050-2855 (C-H), 1640 $(\mathrm{C}=\mathrm{N}), 1570-1540(\mathrm{C}=\mathrm{C}$ aromatic $), 1281(\mathrm{C}-\mathrm{N}) .{ }^{1} \mathrm{H}-$ NMR (DMSO-d ${ }_{6}$ ) ppm: $\delta 2.86\left(\mathrm{~s}, 24 \mathrm{H}, 8 \mathrm{CH}_{3}\right), 6.49(\mathrm{~d}$, $2 \mathrm{H}$, aromatic), 7.32-7.42 (m, $4 \mathrm{H}$, aromatic). ${ }^{13} \mathrm{C}-\mathrm{NMR}$ $\left(\left(\mathrm{CD}_{3}\right)_{2} \mathrm{CO}\right)$ ppm: $\delta 40.79,115.12,119.50,123.12$, $127.47,137.93,143.69,160.62$.

\subsection{Synthesis of [Co(btmgn $\left.) \mathrm{Cl}_{2}\right]$}

To an aqueous solution, $10 \mathrm{~mL}$, of cobalt(II) chloride $(1.0 \mathrm{~g}, 0.77 \mathrm{mmol})$ a $15 \mathrm{~mL}$ ethanolic solution of the organic ligand (btmgn), (3 g, $\sim 0.85 \mathrm{mmol}$ ) was added dropwise with constant stirring over about $15 \mathrm{~min}$. The clear solution was allowed to stand for 2 weeks (some preparations needed longer time). Uniform, deep blue crystals, crystals suitable for X-ray measurements were collected and air-dried. There was a yield of $0.85 \mathrm{~g}$, about $76 \%$ with respect to the metal. FTIR: 3059$2860(\mathrm{C}-\mathrm{H}), 1558(\mathrm{C}=\mathrm{N}), 1520(\mathrm{C}=\mathrm{C}$ aromatic $), 1278$ (C-N) $\mathrm{cm}^{-1}$. UV-Vis. 237.0, 348.0, 611.1, $648.0 \mathrm{~nm}$ (Nujal mull).

\subsection{XRD measurement}

Single crystal X-ray diffraction data were collected on an Enraf-Nonius 590 Kappa CCD single crystal diffractometer with graphite monochromated $\operatorname{MoK} \alpha(\lambda=$ $0.71073 \AA$ ) radiation. Intensity data were collected at room temperature using $\varphi$ and $\omega$ scans; the crystal to detector distance was $40 \mathrm{~mm}$. Data processing was performed using the maXus program package, ${ }^{16}$ the cell refinement and data reduction were carried with Denzo and Scalepak's programs; ${ }^{17}$ the crystal structures were solved by direct methods using the SHELXS program $^{18}$ which revealed the positions of all nonhydrogen atoms. The crystal structure was refined by full matrix least square refinement based on $\mathrm{F}^{2}$ using the SHELX program package. ${ }^{18}$ The temperature factors of all non-hydrogen atoms were refined anisotropically. The hydrogen atoms were calculated using a riding model with $\mathrm{C}-\mathrm{H}=0.96 \AA$ A . Multiscan absorption corrections were applied to all data sets using the program SORTAV. ${ }^{19}$ Crystallographic data and data collection details are summarized in Table 1.

Supplementary data are available from the CCDC, 12 Union Road, Cambridge CB2 1EZ, UK on request, quoting the deposition number CCDC-1037138 or the DOI for this paper. These data can be obtained free of charge at www.ccdc.cam.ac.uk/conts/retrieving. html or fax: (internat.) +44-1223/336-033; E-mail: deposit@ccdc.cam.ac.uk.

\subsection{Computational Details}

All calculations for the $\left[\mathrm{Co}(\mathrm{btmgn}) \mathrm{Cl}_{2}\right]$ complex as well as the free ligand (btmgn) were carried out using Gaussian 03W software. ${ }^{20}$ The quantum chemical calculations have been performed using the B3LYP level of theory supplemented with the 6-311G(d,p) basis set. GaussView4.121 and Chemcraft ${ }^{22}$ have been used to draw the structures of the optimized geometries and to draw the HOMO and LUMO pictures. The input file was taken from the CIF obtained from our reported $\mathrm{X}$-ray single crystal measurement. The geometries were optimized by minimizing energies with respect to all geometrical parameters without imposing any 
Table 1. Crystal data and structure refinement of the $\left[\mathrm{Co}(\mathrm{btmgn}) \mathrm{Cl}_{2}\right]$ complex.

\begin{tabular}{|c|c|c|}
\hline Empirical formula & $\mathrm{C}_{20} \mathrm{H}_{30} \mathrm{Cl}_{2} \mathrm{CoN}_{6}$ & \\
\hline Formula weight & 484.33 & \\
\hline Temperature & 298(2) K & \\
\hline Wavelength & $0.71073 \AA$ & \\
\hline Crystal system & monoclinic & \\
\hline Space group & $\mathrm{P} 2{ }_{1} / \mathrm{c}$ & \\
\hline \multirow[t]{3}{*}{ Unit cell dimensions } & $\mathrm{a}=11.385(2) \AA$ & $\alpha=90^{\circ}$ \\
\hline & $\mathrm{b}=11.318(2) \AA$ & $\beta=95.59(3)^{\circ}$ \\
\hline & $\mathrm{c}=18.339(4) \AA$ & $\gamma=90^{\circ}$ \\
\hline Volume & $2351.8(8) \AA^{3}$ & \\
\hline $\mathrm{Z}$ & 4 & \\
\hline Density (calculated) & $1.368 \mathrm{Mg} / \mathrm{m}^{3}$ & \\
\hline Absorption coefficient & $0.975 \mathrm{~mm}^{-1}$ & \\
\hline $\mathrm{F}(000)$ & 1012 & \\
\hline Crystal size & $0.12 \times 0.04 \times 0.03 \mathrm{~mm}^{3}$ & \\
\hline Theta range for data collection & 3.00 to $24.99^{\circ}$ & \\
\hline Index ranges & $-13<=\mathrm{h}<=13,-13<=\mathrm{k}<=12,-21<=\mathrm{l}<=21$ & \\
\hline Reflections collected & 7011 & \\
\hline Independent reflections & $4115[\mathrm{R}(\mathrm{int})=0.0408]$ & \\
\hline Completeness to theta $=24.99^{\circ}$ & $99.30 \%$ & \\
\hline Max. and min. transmission & 0.9713 and 0.8920 & \\
\hline Refinement method & Full-matrix least-squares on $\mathrm{F}^{2}$ & \\
\hline Data / restraints / parameters & $4115 / 0$ / 271 & \\
\hline Goodness-of-fit on $\mathrm{F}^{2}$ & 1.009 & \\
\hline Final $\mathrm{R}$ indices $[\mathrm{I}>2 \sigma(\mathrm{I})]$ & $\mathrm{R} 1=0.0397, \mathrm{wR} 2=0.0704$ & \\
\hline $\mathrm{R}$ indices (all data) & $\mathrm{R} 1=0.0859, \mathrm{wR} 2=0.0829$ & \\
\hline Extinction coefficient & $0.0020(4)$ & \\
\hline Largest diff. peak and hole & 0.251 and -0.267 e. $\AA^{-3}$ & \\
\hline
\end{tabular}

molecular symmetry constraints. The true energy minimum at the optimized geometry of the studied compounds was confirmed as indicated by the absence of any imaginary frequency modes. The electronic spectra of the studied compounds were calculated by the TD-DFT method. The natural bond orbital (NBO) calculations ${ }^{23}$ were performed using NBO 3.1 program as implemented in the Gaussian $03 \mathrm{~W}$ package at the DFT/B3LYP level. The second order Fock matrix was carried out to evaluate the donor-acceptor interactions in the NBO basis. $^{24}$

\section{Results and Discussion}

\subsection{Structure of the ligand}

The ligand (btmgn) was prepared by reaction of TCFH and 1,8-diaminonaphthalene using DMF as a solvent and following the reported method for preparation of guanidine using $\mathrm{TCFH}^{25}$ (scheme 1). The NMR spectra are presented in figure S1 (Supplementary Information).

The spectral analysis of the btmgn ligand confirmed the expected structure. The IR spectrum of the btmgn

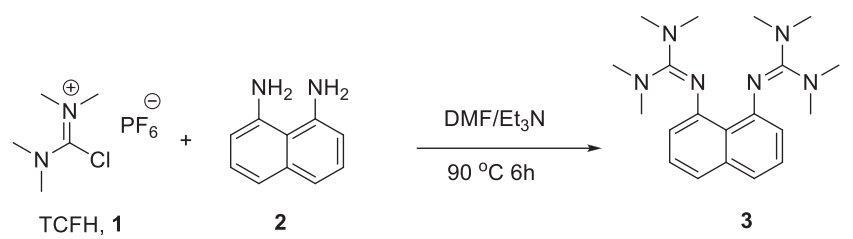

Scheme 1. Synthesis of Ligand.

showed an absorption peak at $1640 \mathrm{~cm}^{-1}$ corresponding to the $\mathrm{C}=\mathrm{N}$ groups, and the expected bands for aromatic structure. The corresponding band in the $\left[\mathrm{Co}(\mathrm{btmgn}) \mathrm{Cl}_{2}\right]$ is located at about $1558 \mathrm{~cm}^{-1}$. The large red shift upon coordination indicates the strong ligand-metal interaction.

${ }^{1} \mathrm{H}$ NMR spectrum of the btmgn showed a multiplet corresponding to the four aromatic protons $\mathrm{H}-2, \mathrm{H}-3$, $\mathrm{H}-6$ and $\mathrm{H}-7$ in the region 7.42-7.32 ppm. A doublet ( $\delta=6.49, \mathrm{~J}=7.1 \mathrm{~Hz}$ ) corresponding to the two protons $\mathrm{H}-4$ and H-5 was observed. A singlet at $\delta 2.86$ ppm corresponding to the twenty four hydrogens of the eight equivalent $\mathrm{N}$-methyl groups was also observed.

${ }^{13} \mathrm{C}$-NMR spectrum of btmgn showed the expected signals. A signal at $160.2 \mathrm{ppm}$ corresponding to the two equivalent $\mathrm{C}=\mathrm{N}$ groups was observed. Six signals 
corresponding to the ten aromatic carbons showed in the region $143.69-115.12 \mathrm{ppm}$. A signal at $\delta 40.78 \mathrm{ppm}$ assigned to the carbons of the eight equivalent methyl groups was also observed.

\section{$3.2 X$-ray Crystal Structure of [Co(btmgn $\left.) \mathrm{Cl}_{2}\right]$}

The complex [Co(btmgn $\left.) \mathrm{Cl}_{2}\right]$, crystallizes with monoclinic symmetry in the space group $\mathrm{P} 2_{1} / \mathrm{c}$. The asymmetric unit of the cell contains one formula unit of the monomeric complex, thus the unit cell comprises four symmetrically equivalent complex molecules. The cobalt atom is distorted tetrahedrally coordinated by two chlorine atoms and the chelating guanidine ligand. Figure 1 shows the molecular structure of this monomeric complex, the interatomic distances as well as the bond angles are listed in table S1 (Supplementary Information). The $\mathrm{Cl}-\mathrm{Co}-\mathrm{Cl}$ bond angle is $112.94(4)^{\circ}$ and thus close to the ideal tetrahedral angle. As expected, the two Co-N distances in this complex are very similar: Co-N1: 1.994(2) $\AA$ and Co-N4: 1.996(2) $\AA$. The $\mathrm{N}-\mathrm{Co}-\mathrm{N}$ bite angle of the chelating guanidine ligand is $90.18^{\circ}$. This value compares quite well with the data of $89.69^{\circ}$ and $90.12^{\circ}$ found for the corresponding complexes of $\mathrm{NiCl}_{2}$ and $\mathrm{NiBr}_{2}$, respectively. ${ }^{26}$ These two compounds crystallize in the same space group and with similar unit cell dimensions and thus can be regarded to be isotypic with the presently discussed $\left[\mathrm{Co}(\mathrm{btmgn}) \mathrm{Cl}_{2}\right]$ complex. All compounds using 1,8-bis(tetramethylguanidino)naphthalene as chelating

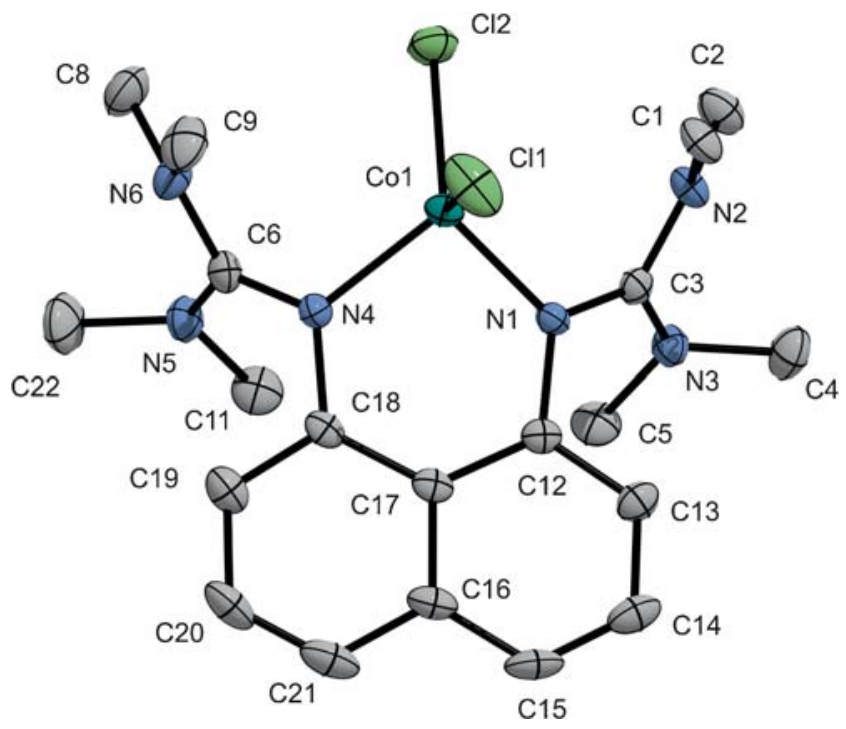

Figure 1. Structure and atom numbering scheme of the $\left[\mathrm{Co}\right.$ (btmgn) $\left.\mathrm{Cl}_{2}\right]$ complex. The hydrogen atoms have been omitted from the drawing for clarity. All atoms are drawn with ellipsoids of $30 \%$ probability level. agent have in common, that the two tetramethylguanidino groups are in a cis-type position to the plane formed by the naphthalene rings. This was also found for the very similar compound bis(tetramethylguanidino)benzenedichlorocobalt(II). ${ }^{27}$

Figure 2 depicts the packing of monomeric complex molecules in a view along the crystallographic $b$ axis. It is evident that the crystal structure contains non-polar and polar regions. The non-polar regions are formed by the naphthalene rings located perpendicular to the $b c$ plane at the height $x=0$. In the range between $x \sim 1 / 4$ and $x \sim 1 / 3$ numerous polar interactions between the complex molecules can be observed. A number of hydrogen bridge bonds between some protons of methyl residuals in the tetramethylguanidino groups and the chlorine atom with $\mathrm{Cl}-\mathrm{H}$ distances well below $3.00 \AA$ can be found (see figure 3). Additional $\mathrm{Cl}-\mathrm{H}$ bridge occurs between the $\mathrm{H} 15$ hydrogen atom of the naphthalene ring and the $\mathrm{Cl} 1$ atoms of the adjacent molecular layers.

\subsection{Optimized molecular structure}

The optimized geometric structures and atomic numbering of the studied complex are shown in figure 4 . The predicted geometric parameters (bond lengths and bond angles) of the investigated structures are collected in table S2 (Supplementary Information). Most of the bond lengths are overestimated except some of the $\mathrm{C}-\mathrm{N}$ bonds which have smaller bond lengths than the experimental values. Generally, the bond lengths and bond angles are predicted very well. The maximum deviations of the calculated bond length values from the experimental data are 0.051 and $0.031 \AA$ for the $\mathrm{Co}-\mathrm{Cl} 2$ and $\mathrm{Co}-\mathrm{Cl} 3$, respectively. The calculated $\mathrm{Co}-\mathrm{Cl} 2$ and Co-Cl3 bond distances are $2.316 \AA$ (exp. $2.265 \AA$ ) and $2.264 \AA$ (exp. $2.233 \AA$ ). The percentage error in these

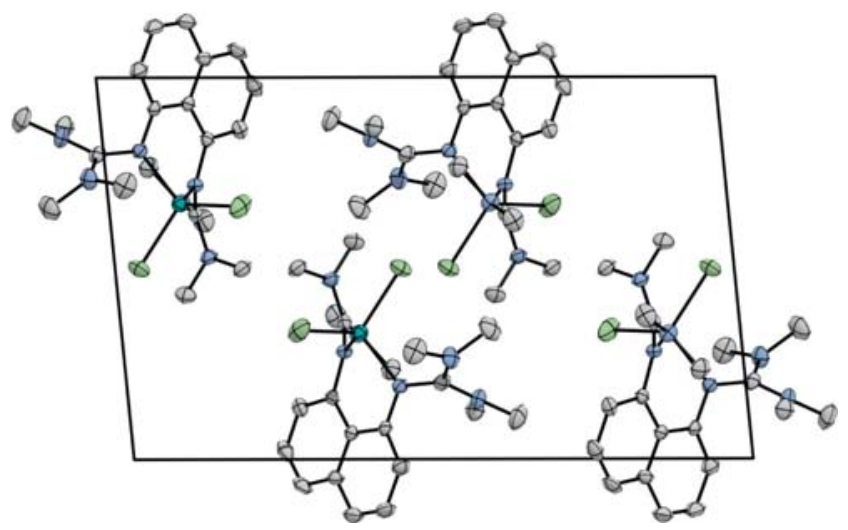

Figure 2. Unit cell content of $\left[\mathrm{Co}(\mathrm{btmgn}) \mathrm{Cl}_{2}\right]$ complex. The structure is shown in a view along the monoclinic $b$-axis. 


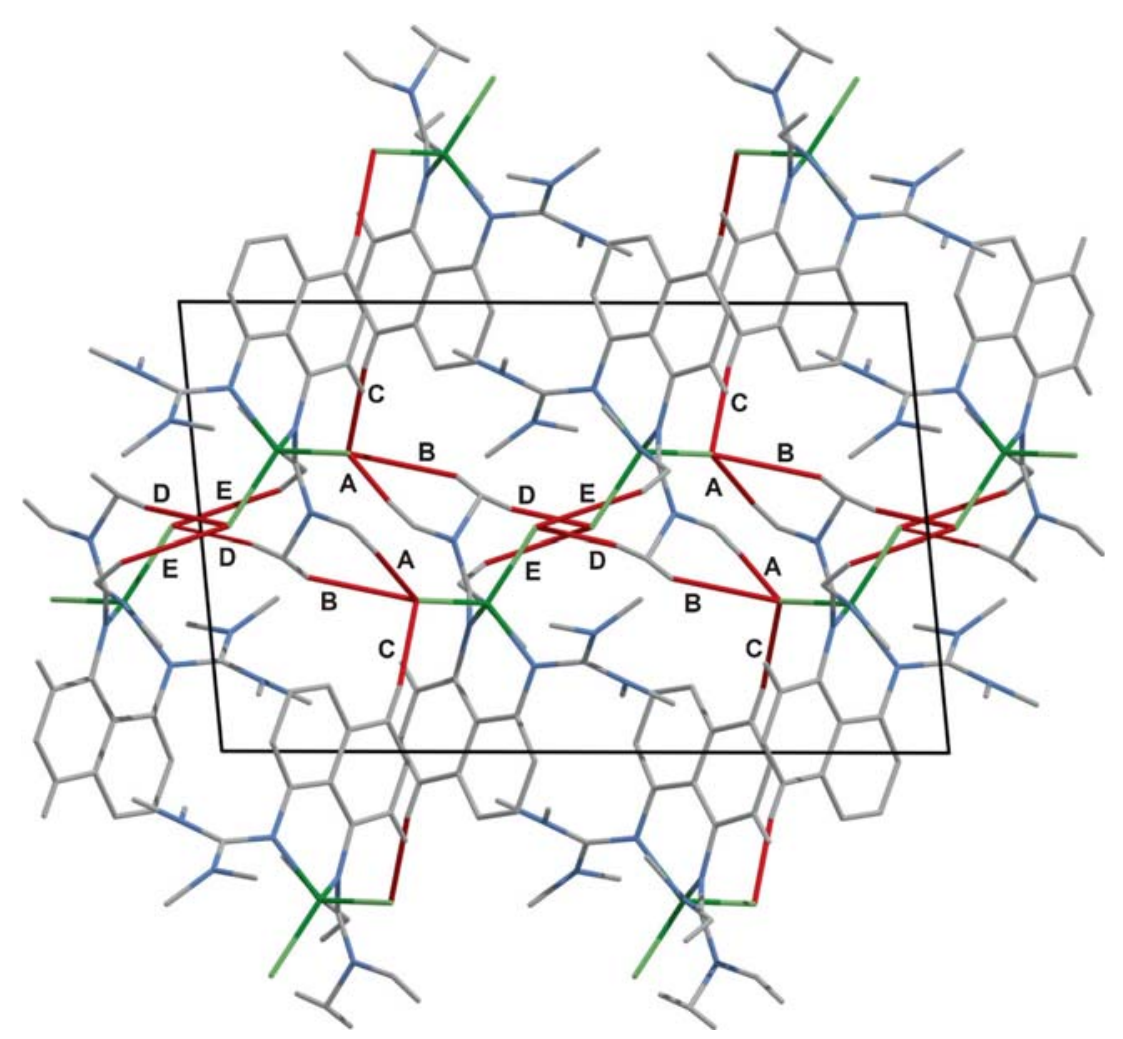

Figure 3. Hydrogen bonds in the structure of $\left[\mathrm{Co}(\mathrm{btmgn}) \mathrm{Cl}_{2}\right]$ complex. The Cl-H interactions shorter than $3.00 \AA$ are shown as red bars (A: Cl1-H1B: 2.762 A; B: Cl1-H2B: $2.841 \AA$ A C: Cl1-H15: 2.731 $\AA$; D: Cl2-H2A: $2.930 \AA$ A; E: Cl2-H4B: $2.858 \AA$ ). The different $\mathrm{Cl}-\mathrm{H}$ interactions are marked by the capital lettersA-E in this figure. The structure is shown in a view along the monoclinic $b$-axis.

bond distances does not exceed $2.3 \%$. These deviations are mainly due to the phase difference between the calculations and the experimental data. The former is free from the crystal field effects. In agreement with the experimental X-ray structure, the calculations predicted that the two $\mathrm{Co}-\mathrm{Cl}$ bond distances are not identical.

In the present section, the structural variations in the ligand geometric parameters due to coordination between the $\mathrm{Co}^{2+}$-ion and the ligand through N4 and N7 atoms have been discussed. Most of the ligand geometric parameters undergo very little variations due to the formation of the Co-N bonds. The $\mathrm{C} 10-\mathrm{N} 4$ and $\mathrm{C} 11-$ N7 bond distances are increased by $0.04 \AA$ while the C10-N10 and C11-N9 bond distances are decreased by the same magnitude. The rest of the bond distances are changed very little. Moreover, the most significant bond angle changes occur around the coordination sites (N4 and N7). The C10-N4-C40, N4-C10-N5, N4C10-N6, C11-N7-C43, N7-C11-N8 and N7-C11-N9 bond angle changes are in the range of 4.36-4.74. The C10-N4-C40-C44, C10-N4-C40-C41, C11-N7C43-C46 and C11-N7-C43-C41 dihedral angles of the free ligand and $\left[\mathrm{Co}(\mathrm{btmgn}) \mathrm{Cl}_{2}\right]$ complex are calculated in the range of the values of the ranges should be 39.7$46.2^{\circ}$ and $32.0-36.9^{\circ}$, respectively. We noted that the formation of the $\mathrm{Co}-\mathrm{N}$ bonds decreases the deviation of the two $-\mathrm{C}\left(\mathrm{N}\left(\mathrm{CH}_{3}\right)_{2}\right)_{2}$ from the naphthalene ring plane. Also, the two tetramethylguanidino groups are in a cistype position to the plane formed by the naphthalene rings both in the btmgn and $\left[\mathrm{Co}(\mathrm{btmgn}) \mathrm{Cl}_{2}\right]$.

\subsection{Natural atomic charges}

Distribution of positive and negative charges has vital role in the application of quantum chemical calculations to molecular system because of atomic charges affect dipole moment, molecular polarizability, electronic structure, acidity-basicity behavior and other properties of molecular system. ${ }^{28}$ In this regard, the natural atomic charges (NAC) were calculated using the DFT B3LYP/6-311G(d,p). The calculated natural charges at the different atomic sites of the $\left[\mathrm{Co}(\mathrm{btmgn}) \mathrm{Cl}_{2}\right] \mathrm{com}$ plex as well as the free ligand (btmgn) are given in table 2. All the $\mathrm{H}$-atoms are electropositive where the natural atomic charge values at these sites are in the 

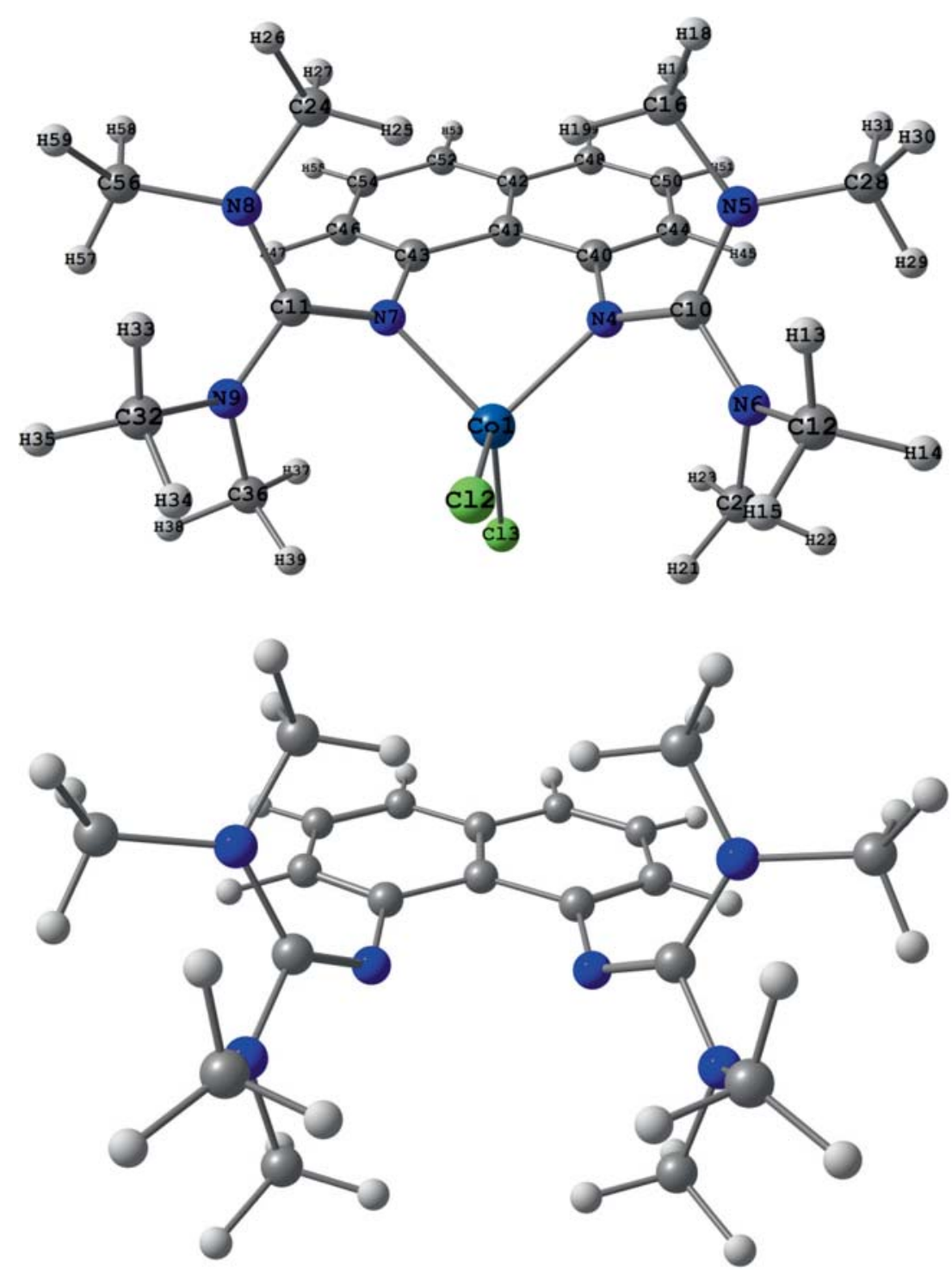

Figure 4. The optimized molecular structure of the free ligand btmgn (lower) and the complex $\left[\mathrm{Co}((\mathrm{btmgn})) \mathrm{Cl}_{2}\right]$ (upper).

range 0.2209-0.2641. Moreover the aromatic protons are more electropositive than the methyl H-atoms. In contrast, the aromatic and the methyl carbon atoms are electronegative. The $\mathrm{C} 10, \mathrm{C} 11, \mathrm{C} 40$ and $\mathrm{C} 43$ atoms have positive natural atomic charges as these $\mathrm{C}$-sites bonded to the strong electronegative $\mathrm{N}$-atoms. The charge densities at all the $\mathrm{N}$-atoms of the free ligand (btmgn) are negative $(-0.4859$ to -0.5374$)$. The NAC values at the $\mathrm{N} 4$ and $\mathrm{N} 7$ atomic sites are calculated to be -0.5373 and -0.5374 respectively indicating the higher basicity of these N-sites compared to the others. It is noted that the NAC values at the N4 (-0.7436) and $\mathrm{N} 7(-0.7435)$ of the $\left[\mathrm{Co}(\mathrm{btmgn}) \mathrm{Cl}_{2}\right]$ complex are more negative than the free ligand. The coordination between the $\mathrm{Co}$ (II) ion and the ligand (btmgn) via the N4 and N7 coordination centers increases their negative charge values by 0.21 unit. The NAC values at the other $\mathrm{N}$-sites of the free and coordinated btmgn ligand are almost the same. Furthermore, the NAC values of the Co1, Cl2 and $\mathrm{Cl} 3$ are calculated to be $+1.4314,-0.7942$ and -0.7686 , respectively. The two coordinated $\mathrm{Cl}$-atoms are not equivalent. We noted that the longer $\mathrm{Co}-\mathrm{Cl} 2$ bond has more electronegative chlorine atom than the shorter $\mathrm{Co}-\mathrm{Cl} 3$.

\subsection{Molecular electrostatic potential}

Molecular electrostatic potential (MEP) is a very useful property for analyzing and predicting molecular reactive behavior. It is very useful three dimensional diagrams used to visualize the charge distributions and charge related properties of molecules as well as in assessing the molecules reactivity towards positively or negatively charged reactants. The MEP is typically 
Table 2. The calculated natural atomic charges of the $\left[\mathrm{Co}(\mathrm{btmgn}) \mathrm{Cl}_{2}\right]$ complex and the free ligand (btmgn).

\begin{tabular}{lrrrrr}
\hline Atom $^{\mathrm{a}}$ & {$\left[\mathrm{Co}(\mathrm{btmgn}) \mathrm{Cl}_{2}\right]$} & Btmgn & Atom & {$\left[\mathrm{Co}(\mathrm{btmgn}) \mathrm{Cl}_{2}\right]$} & \multicolumn{1}{l}{ btmgn } \\
\hline Co1 & 1.4314 & & $\mathrm{H} 31$ & 0.2292 & 0.2165 \\
C12 & -0.7942 & & $\mathrm{C} 32$ & -0.4833 & -0.4763 \\
C13 & -0.7686 & & $\mathrm{H} 33$ & 0.2428 & 0.2418 \\
N4 & -0.7436 & -0.5373 & $\mathrm{H} 34$ & 0.2600 & 0.2103 \\
N5 & -0.4715 & -0.5041 & $\mathrm{H} 35$ & 0.2209 & 0.2249 \\
N6 & -0.4373 & -0.4860 & $\mathrm{C} 36$ & -0.4996 & -0.4734 \\
N7 & -0.7435 & -0.5374 & $\mathrm{H} 37$ & 0.2640 & 0.2540 \\
N8 & -0.4715 & -0.5041 & $\mathrm{H} 38$ & 0.2271 & 0.2201 \\
N9 & -0.4376 & -0.4859 & H39 & 0.2540 & 0.2156 \\
C10 & 0.6775 & 0.6395 & C40 & 0.1764 & 0.1795 \\
C11 & 0.6774 & 0.6396 & C41 & -0.0780 & -0.0787 \\
C12 & -0.4833 & -0.4763 & C42 & -0.0378 & -0.0421 \\
H13 & 0.2429 & 0.2418 & C43 & 0.1763 & 0.1795 \\
H14 & 0.2209 & 0.2249 & C44 & -0.2779 & -0.2937 \\
H15 & 0.2600 & 0.2103 & H45 & 0.2354 & 0.2320 \\
C16 & -0.4726 & -0.4695 & C46 & -0.2778 & -0.2937 \\
H17 & 0.2310 & 0.2251 & H47 & 0.2354 & 0.2320 \\
H18 & 0.2320 & 0.2226 & C48 & -0.2359 & -0.2445 \\
H19 & 0.2418 & 0.2379 & H49 & 0.2374 & 0.2310 \\
C20 & -0.4996 & -0.4734 & C50 & -0.2213 & -0.2301 \\
H21 & 0.2539 & 0.2156 & H51 & 0.2406 & 0.2347 \\
H22 & 0.2271 & 0.2201 & C52 & -0.2358 & -0.2445 \\
H23 & 0.2641 & 0.2540 & H53 & 0.2374 & 0.2310 \\
C24 & -0.4725 & -0.4695 & C54 & -0.2213 & -0.2301 \\
H25 & 0.2418 & 0.2380 & H55 & 0.2406 & 0.2347 \\
H26 & 0.2320 & 0.2226 & C56 & -0.4813 & -0.4780 \\
H27 & 0.2311 & 0.2251 & H57 & 0.2485 & 0.2480 \\
C28 & -0.4813 & -0.4780 & H58 & 0.2293 & 0.2166 \\
H29 & 0.2484 & 0.2480 & H59 & 0.2294 & 0.2195 \\
H30 & 0.2294 & 0.2195 & & & \\
& & & & &
\end{tabular}

a Atom numbering refers to Figure 4

visualized through mapping its values onto the surface reflecting the molecules boundaries so it allows us to visualize the size and shape of molecules. The MEP diagrams of the free ligand (btmgn) and its $\left[\mathrm{Co}(\mathrm{btmgn}) \mathrm{Cl}_{2}\right]$ complex are shown in figure 5. In this particular, the regions of high electron density appear in red (electrophilic reactivity) while the blue regions are related to electron deficiency (nucleophilic reactivity). The resulting overall MEP of the ligand (btmgn) leaves no doubt that the nitrogen atoms carrying methyl groups (N5, N6, N8 and N9) already are not attracted to a positive test charge such as $\mathrm{Co}^{2+}$ while the opposite is true for the N4 and N7 atoms. From the present investigations, we could conclude that the N4 and N7 atoms are the most reactive nucleophilic centers for the coordination with the $\mathrm{Co}^{2+}$ ion. Hence, the high basicity of the two guanidinic nitrogen centers (N4 and N7) is evident. Moreover, the MEP picture of the $\left[\mathrm{Co}(\mathrm{btmgn}) \mathrm{Cl}_{2}\right]$ complex indicated that the MEP values around the two $\mathrm{Cl}$-sites are not equivalent. These results are in good agreement with the calculated NAC values.

\subsection{Nonlinear optical properties}

The calculated electronic properties such as dipole moment $(\mu)$, polarizability $\left(\alpha_{0}\right)$, first hyperpolarizability $\left(\beta_{0}\right)$, HOMO and LUMO energies as well as their energy gap are given in table 3 . These electronic properties have strong relations to the nonlinear optical activity of compound. The present calculations indicated that the $\left[\mathrm{Co}(\mathrm{btmgn}) \mathrm{Cl}_{2}\right]$ has higher dipole moment and polarizability than the free ligand. Also, the calculated first hyperpolarizability $\left(\beta_{0}\right)$ values of the btmgn and $\left[\mathrm{Co}(\mathrm{btmgn}) \mathrm{Cl}_{2}\right]$ are 457.4870 a.u and 837.3271 a.u, respectively. Moreover, the lower energy gap $(\Delta \mathrm{E})$ indicates the more facile electronic transition which is a basic requirement for good nonlinear optical materials. The $\left[\mathrm{Co}(\mathrm{btmgn}) \mathrm{Cl}_{2}\right]$ has lower energy gap 

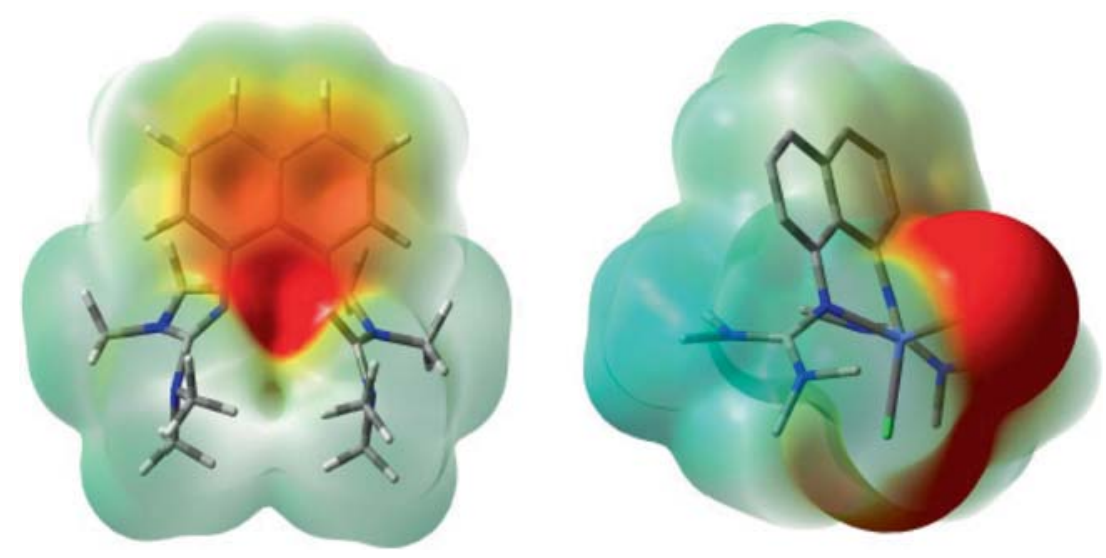

Figure 5. Molecular electrostatic potentials mapped on the electron density surface for free ligand (btmgn) and $\left[\mathrm{Co}(\mathrm{btmgn}) \mathrm{Cl}_{2}\right]$ complex calculated by DFT/B3LYP method. For the $\left[\mathrm{Co}(\mathrm{btmgn}) \mathrm{Cl}_{2}\right]$, the $\mathrm{H}$-atoms are omitted for clarity.

Table 3. The dipole moments components $\mu$ (D), the average polarizability $\alpha_{0}$ (a.u) and the first hyperpolarizability $\beta_{0}$ (a.u) of the studied compounds.

\begin{tabular}{lcccrr}
\hline Parameter & {$\left[\mathrm{Co}(\mathrm{btmgn}) \mathrm{Cl}_{2}\right]$} & btmgn & Parameter & {$\left[\mathrm{Co}(\mathrm{btmgn}) \mathrm{Cl}_{2}\right]$} & \multicolumn{1}{c}{ btmgn } \\
\hline$\mu_{\mathrm{x}}$ & -0.004 & -0.006 & $\beta_{\mathrm{xyy}}$ & 0.8458 & -0.5237 \\
$\mu_{\mathrm{y}}$ & 4.470 & -3.950 & $\beta_{\mathrm{yyy}}$ & -232.7684 & -130.1947 \\
$\mu_{\mathrm{z}}$ & 8.683 & 2.759 & $\beta_{\mathrm{xxz}}$ & -1.1379 & 0.8055 \\
$\mu_{\text {tot }}$ & 9.766 & 4.818 & $\beta_{\mathrm{xyz}}$ & 914.8886 & 591.0694 \\
$\alpha_{\mathrm{xx}}$ & 358.823 & 327.880 & $\beta_{\mathrm{yyz}}$ & 240.9203 & 12.5230 \\
$\alpha_{\mathrm{xy}}$ & -0.033 & -8.937 & $\beta_{\mathrm{xzz}}$ & 0.1853 & 0.2940 \\
$\alpha_{\mathrm{yy}}$ & 356.760 & 249.173 & $\beta_{\mathrm{yzz}}$ & 15.2282 & 236.6741 \\
$\alpha_{\mathrm{xz}}$ & 0.063 & 26.499 & $\beta_{\mathrm{zzz}}$ & -0.0390 & 0.0335 \\
$\alpha_{\mathrm{yz}}$ & -12.255 & 63.602 & $\beta_{\mathrm{xyy}}$ & -74.8864 & -125.2531 \\
$\alpha_{\mathrm{zz}}$ & 232.653 & 248.899 & $\beta_{\mathrm{yyy}}$ & 320.3787 & 61.6926 \\
$\alpha_{0}$ & 316.080 & 275.320 & $\beta_{\mathrm{x}}$ & -0.3311 & 0.3152 \\
$\mathrm{E}_{\mathrm{HOMO}}$ & -5.018 & -4.380 & $\beta_{\mathrm{y}}$ & 607.2338 & 335.6216 \\
$\mathrm{E}_{\mathrm{LUMO}}$ & -1.186 & -0.334 & $\beta_{\mathrm{z}}$ & 576.5272 & 310.8897 \\
$\Delta \mathrm{E}$ & 3.832 & 4.046 & $\beta_{0}$ & 837.3271 & 457.4870 \\
\hline
\end{tabular}

$(\Delta \mathrm{E})$ than the free ligand. These results indicate that the $\left[\mathrm{Co}(\mathrm{btmgn}) \mathrm{Cl}_{2}\right]$ has better nonlinear optical (NLO) properties than the free organic ligand.

\subsection{Electronic spectra}

The electronic transition from the ground to the first excited state is mainly described by one electron excitation from the highest occupied molecular orbital (HOMO) to the lowest unoccupied molecular orbital (LUMO). ${ }^{29}$ The excitation energy involves the difference between them $\left(\Delta \mathrm{E}=\mathrm{E}_{\mathrm{LUMO}}-\mathrm{E}_{\mathrm{HOMO}}\right)$. The HOMO and LUMO plots of the $\left[\mathrm{Co}(\mathrm{btmgn}) \mathrm{Cl}_{2}\right]$ complex as well as the free ligand (btmgn) drawn by DFT-B3LYP method are shown in figure 6 . In both molecules the
HOMO and LUMO levels are mainly localized over the ligand $\pi$-system. There is significant orbital densities present on the $\mathrm{Co}^{2+}$ and the coordinated $\mathrm{Cl}$-atoms in case of $\left[\mathrm{Co}(\mathrm{btmgn}) \mathrm{Cl}_{2}\right]$. The electronic transition in case of the ligand is mainly $\pi-\pi *$ excitation while in the $\left[\mathrm{Co}(\mathrm{btmgn}) \mathrm{Cl}_{2}\right]$ the electronic transition is mixed $\pi-\pi^{*}$ and d-d transitions.

The more accurate electronic transitions of the ligand (btmgn) and the complex $\left[\mathrm{Co}(\mathrm{btmgn}) \mathrm{Cl}_{2}\right]$ have been investigated by using the time-dependent density functional theory. Electronic absorption spectra calculated by the TD-DFT are presented in figure 7 . For the free ligand, the TD-DFT calculations predicted moderate intensity transition band at $337.2 \mathrm{~nm}(\mathrm{f}=0.2299)$ which is mainly due to $\mathrm{HOMO} \rightarrow \mathrm{LUMO}(83 \%)$ excitation. Of the fifty singlet-singlet electronic excitations calculated 


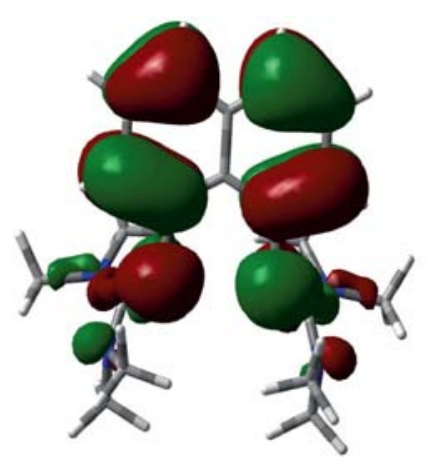

$\mathbf{H}$

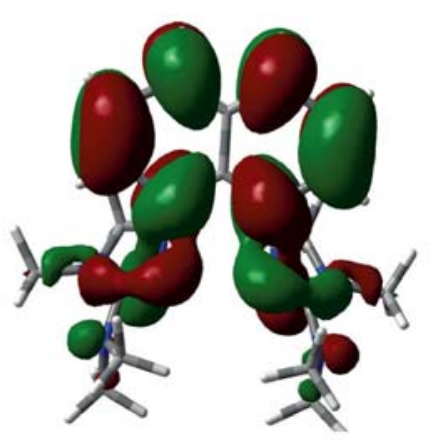

$\mathbf{L}$

(btmgn)

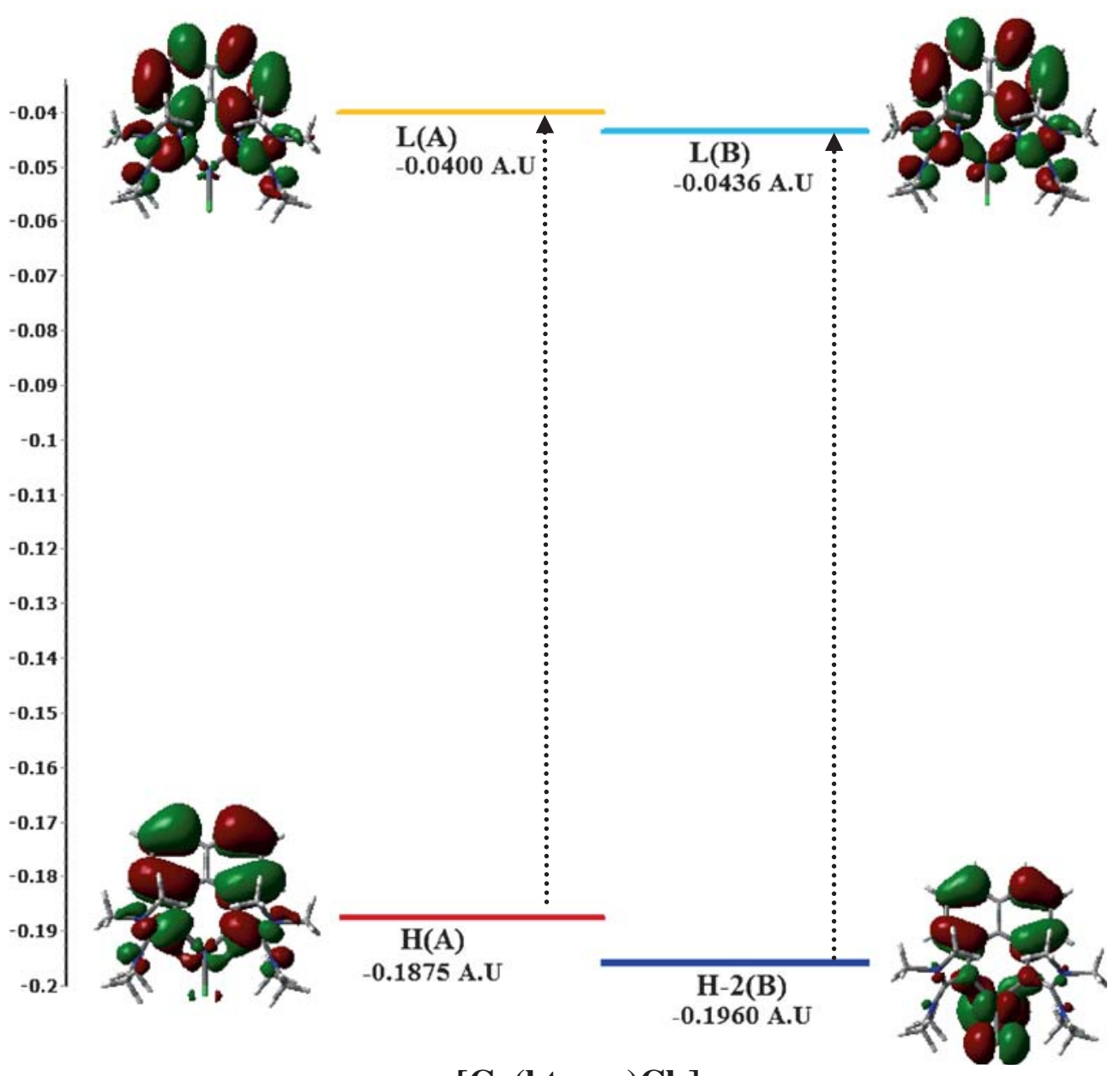

\section{$\left[\mathrm{Co}(\right.$ btmgn $\left.) \mathrm{Cl}_{2}\right]$}

Figure 6. The ground state isodensity surface plots for the frontier molecular orbitals contributed in the electronic transition.

for the $\left[\mathrm{Co}(\mathrm{btmgn}) \mathrm{Cl}_{2}\right]$ complex, a very broad transition band with low intensity $(\mathrm{f}=0.1465)$ has been calculated at $342.6 \mathrm{~nm}$ (exp. $348.0 \mathrm{~nm}$ ) due to the HOMO$2 \rightarrow$ LUMO (53\%) and HOMO $\rightarrow$ LUMO (28\%) excitations. The rest of the transitions bands have very low intensity (table S3, Supplementary Information).

\subsection{Natural bond orbital analysis}

The natural bond orbital (NBO) calculations were performed in order to understand various interactions between the filled and vacant NBOs, which are measure of the intramolecular delocalization of electrons 


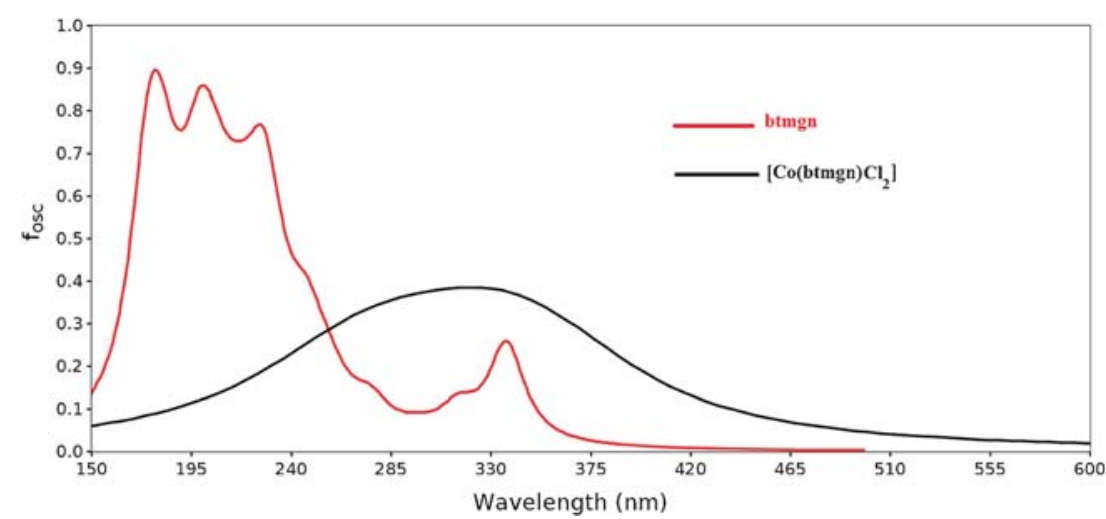

Figure 7. The calculated electronic spectra of the studied compounds using TD-DFT method.

Table 4. The second order perturbation energies $\mathrm{E}^{(2)}(\mathrm{kcal} / \mathrm{mol})$ of the most important charge transfer interactions (donor-acceptor) of the studied compounds using B3LYP method.

\begin{tabular}{|c|c|c|c|}
\hline \multirow[b]{2}{*}{ Donor NBO (i) ${ }^{\mathrm{a}}$} & \multirow[b]{2}{*}{ Acceptor NBO (j) } & \multicolumn{2}{|c|}{$\mathrm{E}^{(2)} \mathrm{kcal} / \mathrm{mol}$} \\
\hline & & btmgn & {$\left[\mathrm{Co}(\mathrm{btmgn}) \mathrm{Cl}_{2}\right]$} \\
\hline $\mathrm{BD}(2) \mathrm{N} 4-\mathrm{C} 10$ & $\mathrm{BD}^{*}(2) \mathrm{C} 40-\mathrm{C} 44$ & 7.66 & 5.38 \\
\hline BD(2)N7-C11 & $\mathrm{BD} *(2) \mathrm{C} 43-\mathrm{C} 46$ & 7.67 & 5.36 \\
\hline $\mathrm{BD}(2) \mathrm{C} 40-\mathrm{C} 44$ & $\mathrm{BD} *(2) \mathrm{C} 41-\mathrm{C} 42$ & 13.20 & \\
\hline $\mathrm{BD}(2) \mathrm{C} 40-\mathrm{C} 44$ & $\mathrm{BD} *(2) \mathrm{C} 48-\mathrm{C} 50$ & 20.90 & 9.35 \\
\hline $\mathrm{BD}(2) \mathrm{C} 41-\mathrm{C} 42$ & $\mathrm{BD} *(2) \mathrm{C} 40-\mathrm{C} 44$ & 19.87 & \\
\hline $\mathrm{BD}(2) \mathrm{C} 41-\mathrm{C} 42$ & BD*(2)C43- C46 & 19.87 & \\
\hline $\mathrm{BD}(2) \mathrm{C} 41-\mathrm{C} 42$ & $\mathrm{BD} *(2) \mathrm{C} 48-\mathrm{C} 50$ & 15.08 & \\
\hline $\mathrm{BD}(2) \mathrm{C} 41-\mathrm{C} 42$ & $\mathrm{BD}^{*}(2) \mathrm{C} 52-\mathrm{C} 54$ & 15.08 & \\
\hline $\mathrm{BD}(2) \mathrm{C} 43-\mathrm{C} 46$ & $\mathrm{BD}^{*}(2) \mathrm{C} 41-\mathrm{C} 42$ & 13.20 & \\
\hline $\mathrm{BD}(2) \mathrm{C} 43-\mathrm{C} 46$ & BD*(2)C52-C54 & 20.90 & 9.35 \\
\hline $\mathrm{BD}(2) \mathrm{C} 48-\mathrm{C} 50$ & $\mathrm{BD} *(2) \mathrm{C} 40-\mathrm{C} 44$ & 15.56 & 8.80 \\
\hline $\mathrm{BD}(2) \mathrm{C} 48-\mathrm{C} 50$ & $\mathrm{BD} *(2) \mathrm{C} 41-\mathrm{C} 42$ & 17.83 & \\
\hline $\mathrm{BD}(2) \mathrm{C} 52-\mathrm{C} 54$ & $\mathrm{BD} *(2) \mathrm{C} 41-\mathrm{C} 42$ & 17.83 & \\
\hline $\mathrm{BD}(2) \mathrm{C} 52-\mathrm{C} 54$ & $\mathrm{BD} *(2) \mathrm{C} 43-\mathrm{C} 46$ & 15.56 & 8.80 \\
\hline LP(1)N4 & BD*(1)N5-C10 & 18.45 & 5.57 \\
\hline LP(1)N4 & $\mathrm{BD} *(2) \mathrm{C} 40-\mathrm{C} 44$ & 13.70 & 3.17 \\
\hline LP(1)N5 & $\mathrm{BD} *(2) \mathrm{N} 4-\mathrm{C} 10$ & 28.00 & 20.60 \\
\hline LP(1)N6 & $\mathrm{BD} *(2) \mathrm{N} 4-\mathrm{C} 10$ & 36.18 & 29.06 \\
\hline LP(1)N7 & $\mathrm{BD} *(1) \mathrm{N} 8-\mathrm{C} 11$ & 18.45 & 5.57 \\
\hline LP(1)N7 & $\mathrm{BD} *(2) \mathrm{C} 43-\mathrm{C} 46$ & 13.70 & 3.17 \\
\hline LP(1)N8 & BD*(2)N7-C11 & 28.01 & 20.61 \\
\hline LP(1)N9 & BD*(2)N7-C11 & 36.24 & 29.03 \\
\hline $\mathrm{LP}(1) \mathrm{Cl} 2$ & LP*(3)Co1 & & 5.14 \\
\hline $\mathrm{LP}(4) \mathrm{Cl} 2$ & $\mathrm{LP}^{*}(3) \mathrm{Co} 1$ & & 29.00 \\
\hline $\mathrm{LP}(4) \mathrm{Cl} 2$ & $\mathrm{LP}^{*}(5) \mathrm{Co} 1$ & & 7.73 \\
\hline $\mathrm{LP}(1) \mathrm{Cl} 3$ & LP*(3)Co1 & & 6.38 \\
\hline $\mathrm{LP}(4) \mathrm{Cl} 3$ & $\mathrm{LP}^{*}(3) \mathrm{Co} 1$ & & 39.17 \\
\hline $\mathrm{LP}(4) \mathrm{Cl} 3$ & $\mathrm{LP} *(5) \mathrm{Co} 1$ & & 3.97 \\
\hline LP(1)N4 & $\mathrm{LP}^{*}(3) \mathrm{Co} 1$ & & 14.10 \\
\hline LP(1)N4 & $\mathrm{LP}^{*}(4) \mathrm{Co} 1$ & & 8.85 \\
\hline LP(1)N4 & $\mathrm{LP}^{*}(6) \mathrm{Co} 1$ & & 6.29 \\
\hline LP(1)N7 & $\mathrm{LP} *(3) \mathrm{Co} 1$ & & 14.09 \\
\hline LP(1)N7 & $\mathrm{LP} *(4) \mathrm{Co} 1$ & & 9.09 \\
\hline LP(1)N7 & $\mathrm{LP}^{*}(6) \mathrm{Co} 1$ & & 6.18 \\
\hline
\end{tabular}

*Bold for the significant $\mathbf{E}^{(2)}$ variations of the $\mathrm{n} \rightarrow \pi *$ at $\mathrm{N} 4$ and $\mathrm{N} 7$.

a Atom numbering refers to figure 4. 
in the studied system. The stabilization energies $\left(\mathrm{E}^{(2)}\right)$ deduced from the NBO calculations for the most significant intramolecular charge transfer interactions are reported in table 4 . The stabilization energy $\mathrm{E}^{(2)}$ values associated with delocalization of electron density between the occupied and unoccupied NBOs correspond to stabilizing donor-acceptor interactions. These stabilization energies are estimated using the second-order perturbation theory. The delocalization of electrons due to the $\pi-\pi^{*}, \mathrm{n}-\pi^{*}$ and $\mathrm{n}-\sigma^{*}$ interactions are responsible for conjugation of the respective $\pi$-bonds leading to a maximum stabilization in the system. It is noted that most of the $\pi-\pi^{*}$ ICT interactions in the naphthalene ring do not occur in the $\left[\mathrm{Co}\right.$ (btmgn) $\left.\mathrm{Cl}_{2}\right]$ complex compared to the free one while the rest of the $\pi-\pi *$ ICT interactions are destabilized. Moreover, the changes in the stabilization energies $\mathrm{E}^{(2)}$ of the $\mathrm{n}-\pi^{*}$ and $\mathrm{n}-\sigma^{*}$ ICT delocalizations are in the range of $7.12-12.88 \mathrm{kcal} / \mathrm{mol}$. The maximum changes in the $\mathrm{E}^{(2)}$ values of these interactions occur for the LP(1)N4 $\rightarrow$ BD*(1)N5-C10/BD*(2)C40$\mathrm{C} 44$ and $\mathrm{LP}(1) \mathrm{N} 7 \rightarrow \mathrm{BD}^{*}(2) \mathrm{N} 7-\mathrm{C} 11 / \mathrm{BD}^{*}(2) \mathrm{N} 7-\mathrm{C} 11$ ICT. It seems that the coordination between the $\mathrm{Co}$ (II) and the ligand (btmgn) via the N4 and N7 atoms strongly destabilize the $\mathrm{n}-\pi^{*}$ interactions resulting from LP(1)N4/N7 more than the others.

Interestingly, the $\mathrm{NBO}$ calculations predicted the ICT $\mathrm{LP}(4) \mathrm{Cl} 2 \rightarrow \mathrm{LP} *(3) \mathrm{Co}$ and $\mathrm{LP}(4) \mathrm{Cl} 3 \rightarrow \mathrm{LP} *(3) \mathrm{Co}$ interactions having $\mathrm{E}^{(2)}$ of 29.00 and $39.17 \mathrm{kcal} / \mathrm{mol}$, respectively. On the other hand, the $\mathrm{LP}(1) \mathrm{N} \rightarrow \mathrm{LP}^{*} \mathrm{Co}$ $(6.29-18.85 \mathrm{kcal} / \mathrm{mol})$ and $\mathrm{LP}(1) \mathrm{N} 4 \rightarrow \mathrm{LP} * \mathrm{Co}(6.18-$ $14.09 \mathrm{kcal} / \mathrm{mol}$ ) have been predicted. It is clear that the,
Table 5. The spin density at the different atomic sites of the $\left[\mathrm{Co}(\right.$ btmgn $\left.) \mathrm{Cl}_{2}\right]$ complex.

\begin{tabular}{|c|c|c|c|}
\hline Co1 & 2.78714 & H31 & 0.00006 \\
\hline $\mathrm{Cl} 2$ & 0.05262 & C32 & -0.00015 \\
\hline $\mathrm{Cl} 3$ & 0.06195 & H33 & 0.00001 \\
\hline N4 & 0.01957 & H34 & 0.00021 \\
\hline N5 & 0.00516 & H35 & 0.00044 \\
\hline N6 & 0.00591 & C36 & 0.00063 \\
\hline N7 & 0.01958 & H37 & 0.00013 \\
\hline N8 & 0.00515 & H38 & 0.00084 \\
\hline N9 & 0.00590 & H39 & 0.00006 \\
\hline $\mathrm{C} 10$ & 0.00354 & $\mathrm{C} 40$ & -0.00508 \\
\hline C11 & 0.00353 & C41 & 0.01015 \\
\hline C12 & -0.00015 & $\mathrm{C} 42$ & -0.00611 \\
\hline H13 & 0.00001 & $\mathrm{C} 43$ & -0.00509 \\
\hline H14 & 0.00044 & C44 & 0.01202 \\
\hline H15 & 0.00021 & H45 & -0.00056 \\
\hline C16 & -0.00034 & $\mathrm{C} 46$ & 0.01203 \\
\hline H17 & 0.00009 & H47 & -0.00056 \\
\hline H18 & 0.00026 & $\mathrm{C} 48$ & 0.00967 \\
\hline H19 & 0.00009 & H49 & -0.00042 \\
\hline $\mathrm{C} 20$ & 0.00063 & C50 & -0.00570 \\
\hline H21 & 0.00006 & H51 & 0.00028 \\
\hline $\mathrm{H} 22$ & 0.00084 & C52 & 0.00968 \\
\hline $\mathrm{H} 23$ & 0.00014 & H53 & -0.00042 \\
\hline $\mathrm{C} 24$ & -0.00034 & C54 & -0.00570 \\
\hline $\mathrm{H} 25$ & 0.00009 & H55 & 0.00028 \\
\hline $\mathrm{H} 26$ & 0.00026 & C56 & -0.00008 \\
\hline $\mathrm{H} 27$ & 0.00009 & H57 & 0.00001 \\
\hline C28 & -0.00009 & H58 & 0.00006 \\
\hline $\mathrm{H} 29$ & 0.00001 & H59 & 0.00049 \\
\hline H30 & 0.00049 & & \\
\hline
\end{tabular}

a Atom numbering refers to figure 4

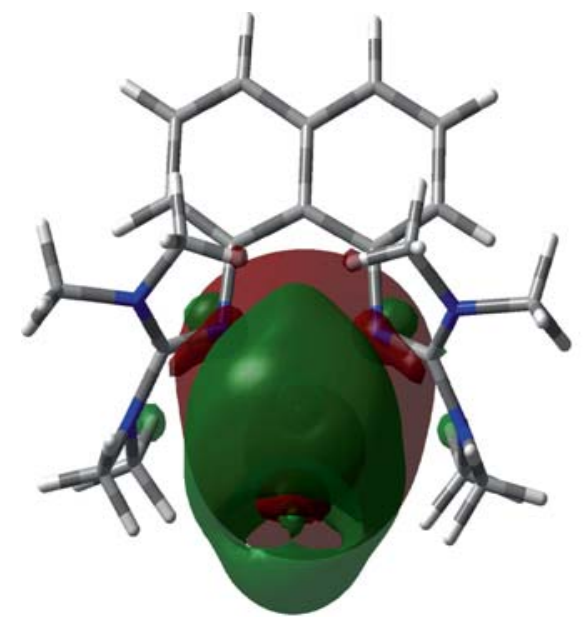

$\mathbf{L P} *(3) \mathbf{C o}$

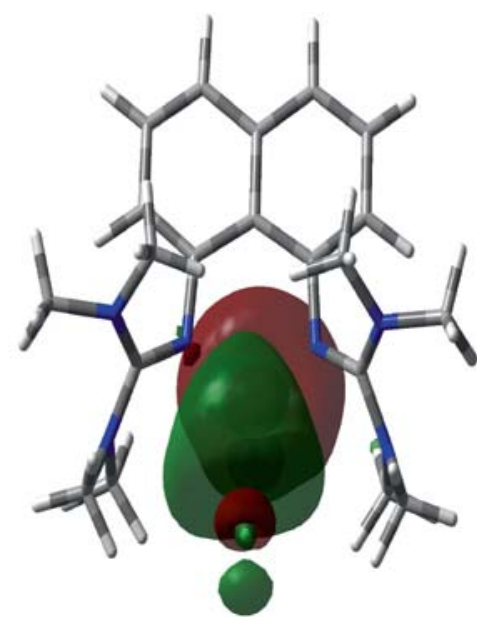

LP*(5)Co

Figure 8. The second order perturbation theory computed donor-acceptor NBO plot for the HS state in complex showing the most significant donoracceptor charge transfer Co-Ligands interactions. 


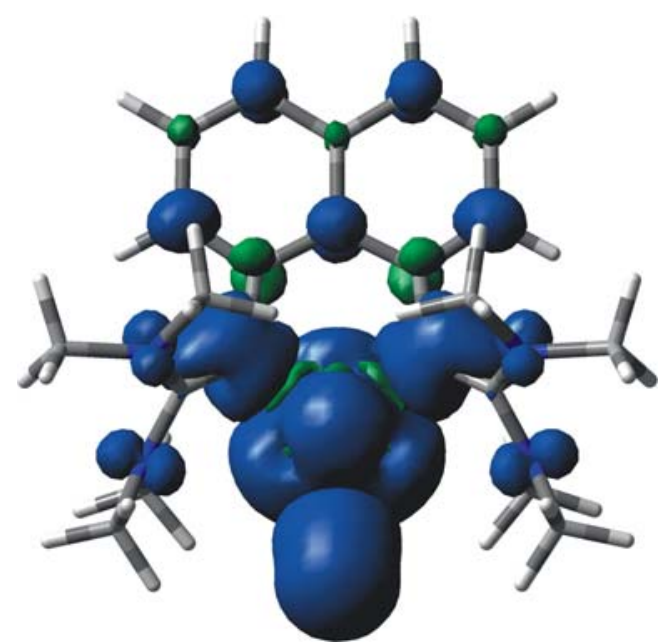

Figure 9. The computed spin density plots for the HS state of complexes; the blue and green for the positive and negative spin densities, respectively.

the two $\mathrm{N} \rightarrow \mathrm{Co}$ interactions are almost equivalent while the $\mathrm{Cl} \rightarrow \mathrm{Co}$ ICT interactions are not. These results are in good agreement with our reported structure investigations. The two $\mathrm{Co}-\mathrm{N}$ bonds are nearly equivalent while the $\mathrm{Co}-\mathrm{Cl} 2$ is weaker (longer) than the $\mathrm{Co}-\mathrm{Cl} 3$. To explore the nature of the d-orbitals involved in the most significant donor acceptor interactions, the NBO plots of these interactions are shown in figure 8 . The composition analysis of these NBOs showed that, the $\mathrm{d}_{\mathrm{x} 2-\mathrm{y} 2}$ as well as the $d_{z 2}$ are the most important metal ion $d-$ orbitals involved in the donor-acceptor charge transfer interactions.

\subsection{Spin density analysis}

In order to investigate the mechanism by which the unpaired d-electrons of the studied high spin $\mathrm{Co}$ (II) complex can distribute some spin density at the other atoms, the spin densities at the different atoms are calculated and listed in table 5. Also, the spin density plots of the high-spin state of the studied $\mathrm{Co}$ (II) complex are shown in figure 9. Generally, we have two possible mechanisms: (1) the molecular orbital that hosts an unpaired electron (metal d orbital) mixes in the atomic orbitals of the ligands (mostly from the donor atoms). As a result, a distribution of positive spin density occurs through out the molecule, hence the resulting distribution of spin density is said to arise from a spin delocalization mechanism; (2) the positive spin at the paramagnetic center may induce some spin density of the opposite sign at the atoms bonded to it which is called the spin polarization mechanism. In this case, a concentration of negative spin density is favored around the ligand donor atoms. In the presented $\left[\mathrm{Co}(\mathrm{btmgn}) \mathrm{Cl}_{2}\right]$, the spin density of the $\mathrm{Co}$ (II) ion is found to be 2.78714. All the atoms coordinated to $\mathrm{Co}$ (II) are found to have positive spin. This illustrates that the spin delocalization mechanism is operational.

\section{Conclusions}

The cobalt(II) chloride complex, $\left[\mathrm{Co}(\mathrm{btmgn}) \mathrm{Cl}_{2}\right]$ of 1,8-bis(tetramethylguanidino)naphthalene (btmgn) ligand has been synthesized and characterized. The Xray crystal structure of the $\left[\mathrm{Co}(\mathrm{btmgn}) \mathrm{Cl}_{2}\right]$ is reported. The geometry of the complex as well as the free btmgn ligand have been calculated using DFT B3LYP/6$311 \mathrm{G}(\mathrm{d}, \mathrm{p})$ method. The calculated geometric parameters showed that the structure of the free ligand is almost the same as in $\left[\mathrm{Co}(\mathrm{btmgn}) \mathrm{Cl}_{2}\right]$ where the two tetramethylguanidino group are in a cis-type position to the plane formed by the naphthalene ring. The $[\mathrm{Co}$ (btmgn $\left.) \mathrm{Cl}_{2}\right]$ has distorted tetrahedral geometry with two equivalent $\mathrm{Co}-\mathrm{N}$ bonds while the two $\mathrm{Co}-\mathrm{Cl}$ bonds are not. The calculated natural atomic charges and molecular electrostatic potential (MEP) map showed that the two guanidinic N-atoms (N4 and N7) have the highest basic character and the most favored nucleophilic centers for the $\mathrm{Co}$ (II) ion attack. The electronic spectra of the btmgn and $\left[\mathrm{Co}(\mathrm{btmgn}) \mathrm{Cl}_{2}\right]$ have been calculated using the TD-DFT method. The latter showed broad band at $342.6 \mathrm{~nm}$ due to the $\mathrm{H}-2 / \mathrm{H} \rightarrow \mathrm{L}$ excitations. The NBO calculations were used to study the different intramolecular charge transfer interactions occur in the studied systems. The FTIR spectra showed strong red shift for the $v_{\mathrm{C}=\mathrm{N}}$ mode due to the coordination between the $\mathrm{Co}(\mathrm{II})$ and the ligand via N4 and N7 atoms. This large red shift upon coordination indicates a strong ligand-metal interaction.

\section{Supplementary Information}

The ${ }^{1} \mathrm{H}$ and ${ }^{13} \mathrm{C}$ NMR spectra of the ligand are given in figure $\mathrm{S} 1$. The experimental bond distances and angles obtained from the X-ray structure of the complex are shown in table S1. The calculated bond distances and angles are given in table S2. The TD-DFT results of the studied compounds are given in table S3. Supplementary Information is available at www.ias.ac.in/ chemsci.

\section{References}

1. T Ishikawa (ed.) 2009 In Superbases for Organic Synthesis (Chichester UK: John Wiley \& Sons) 
2. Alder R W, Bowman P S, Steele W R S and Winterman D R 1968 J. Chem. Soc. Chem. Commun. 723

3. Raab V, Kipke J, Gschwind R M and Sundermeyer J 2002 Chem. Eur. J. 81682

4. Edelmann F T 2008 Adv. Organomet. Chem. 57183

5. Herres-Pawlis S 2009 Nachr. Chem. 5720

6. Wight A P and Davis M E 2002 Chem. Rev. 1023589

7. Herres-Pawlis S, Neuba A, Seewald O, Seshadri T, Egold H, Flçrke U and Henkel G 2005 Eur. J. Org. Chem. 4879

8. Petrovic D, Hill L M R, Jones P G, Tolman W B and Tamm M 2008 Dalton Trans. 887

9. Glçge T, Petrovic D, Hrib C, Jones P G and Tamm M 2009 Eur. J. Inorg. Chem. DOI: 10.1002/ejic.200900570

10. Johnson L K, Killian C M and Brookhart M 1995 J. Am. Chem. Soc. 1176414

11. Bartl F, Brzezinski B, Rzalski B and Zundel G $1998 J$. Phys. Chem. B $\mathbf{1 0 2} 5234$

12. Garczarek F and Gerwert K 2006 Nature 439109

13. Peng S M, Chen C T, Liaw D S, Chen C I and Wang Y 1985 Inorg. Chim. Acta 101 L31

14. Khusniyarov M M, Harms K, Burghaus O, Sundermeyer J, Sarkar B, Kaim W, Slageren J, Duboc C and Fiedler J 1355 Dalton Trans.

15. See, for example: (a) Wieghardt K, Quilitzsch U, Nuber B and Weiss J 1978 Angew. Chem. 90 381; (b) 1978 Angew. Chem. Int. Ed. Engl. 17 351; (c) 1978 Angew. Chem. Int. Ed. Engl. 17351

16. Mackay S, Gilmore C J, Edwards C, Stewart N and Shankl K 1999 In maXus Computer Program for the
Solution and Refinement of Crystal Structures (The Netherlands: Bruker Nonius)

17. Otwinowski Z and Minor W 1997 In Methods in Enzymology C W Carter (ed.) 276

18. Sheldrick G M 2008 Acta Cryst. A64 112

19. Blessing R H 1987 Cryst. Rev. 13

20. Frisch M J et al., 2004 Gaussian-03 Revision C.01 (Wallingford CT: Gaussian, Inc.)

21. Dennington II R, Keith T, Millam J 2007 GaussView Version 4.1 (Shawnee Mission, KS: Semichem Inc.)

22. Zhurko G A and Zhurko D A 2005 Chemcraft: Lite Version Build 08 (Freeware)

23. Glendening E D, Reed A E, Carpenter J E and Weinhold F 1998 NBO Version 3.1 TCI (Madison WI: University of Wisconsin)

24. Reed A E and Curtiss L A F 1988 Chem. Rev. 88 899

25. El-Faham A, Chebbo M R, Abdul Gahni M and Younse G O 2006 J. Heterocycl. Chem. 431

26. Roquette P, Koenig C, Huebner O, Wagner A, Kaifer E, Enders M and Himmel H J 2010 Eur. J. Inorg. Chem. 30 4770

27. Roquette P, Maronna A, Peters A, Kaifer E, Himmel H J, Hauf C, Herz V, Schleidt E W and Scherer W 2010 Chem. Eur. J. 161336

28. Sidir I, Sidir Y G, Kumalar M and Tasal E $2010 \mathrm{~J}$. Mol. Struct. 964134

29. Kurt M, Babu P C, Sundaraganesan N, Cinar M and Karabacak M 2011 Spectrochim. Acta Part A 79 1162 